\title{
PLASMACYTOSIS IN THE BONE MARROW IN RHEUMATOID ARTHRITIS
}

\author{
BY \\ F. G. J. HAYHOE AND D. ROBERTSON SMITH \\ From the Department of Medicine, University of Cambridge
}

(RECEIVED FOR PUBLICATION JULY 25, 1950)

A woman suffering from severe rheumatoid arthritis was found to have a hypochromic microcytic anaemia. The anaemia did not respond to iron by mouth but was treated satisfactorily by intravenous iron. A sternal marrow examination before beginning intravenous iron therapy showed several clumps of up to seven or eight plasma cells, and a percentage of plasma cells amounting to 4.8 in 1,000 marrow cells counted. Many of these plasma cells were vacuolated, with irregularity of the cytoplasmic basophilia, and an occasional plasmablast was seen. Multiple myelomatosis was considered as a possible diagnosis, but further clinical examination and investigations excluded this condition. It was concluded that the finding was incidental, though perhaps related to rheumatoid arthritis.

Numerous studies of the sedimentation rate, colloidal gold tests, and plasma viscosity have shown a disturbance in the serum protein fractions in rheumatoid arthritis, and Perlmann and Kaufman (1946) by electrophoretic analysis of the sera from 23 cases showed that the alpha globulins were raised early in the disease and the gamma globulins later. They suggested that articular and synovial damage may liberate a pathological protein similar in molecular weight and electrophoretic mobility to the gamma globulins.

A more likely theory which has been put forward to explain the gamma globulin increase is that an unknown antigen may act as a stimulus for antibody formation. This is based on the known association between some antibodies and the gamma globulin fraction (Enders, 1944).

Whatever the mechanism of stimulation, the possibility that a marrow plasmacytosis might be found in association with the gamma globulin increase was suggested by the considerable volume of work (Bing and Plum, 1937; Kagan, 1943 ; and many others) which has established a connexion between plasma cells, antibody formation, and hyperglobulinaemia. Much of this work is reviewed by Fagraeus (1948).

It therefore seemed worth finding out whether the plasmacytosis observed in the marrow of our original case was common in rheumatoid arthritis. A series of ten cases of rheumatoid arthritis encountered consecutively and unselected was therefore investigated, and sternal marrow examinations showed that in every case the plasma cell content was increased beyond the usually accepted normal figures. 


\section{Methods}

Preparation of Bone Marrow Smear.-Not more than $0.2 \mathrm{ml}$. of marrow was aspirated from the manubrium or body of the sternum through a Salah needle. Smears were made direct on to clean glass slides and stained by Leishman's method. The error of total cell counts on bone marrow aspirates is so great that they were not performed, but all specimens showed normal cellularity as judged by the cell density in stained films.

Plasma Proteins.-Plasma proteins were estimated by the micro-Kjeldahl technique. The total protein, albumin, globulin, and fibrinogen fractions were determined.

Sedimentation Rate.-The red cell sedimentation rate was measured on oxalated venous blood by Wintrobe's method. The rate was corrected for anaemia using the correction chart of Hynes and Whitby (1938).

\section{Classification of Plasmacytic Elements}

The classification of the plasmacytic elements closely follows that used by Fadem and McBirnie (1950), based on the recommendations of "The Committee for the Clarification of the Nomenclature of Cells and Diseases of the Blood and Bloodforming Organs," and the descriptions below are taken, with minor modifications, from their paper. The degenerating plasmacytes have, however, been further subdivided into cells showing " early homogenous degeneration" and " degenerative plasmacytes" (Fig. 1). Michels (1931) recorded five types of degenerative changes occurring in plasma cells, but this detailed classification was considered unnecessary in the present investigation.

Plasmablast.-The plasmablast varies from 20 to $40 \mu$ in diameter. The nucleus is large, $15-30 \mu$ in diameter, and is surrounded by a thin rim of cytoplasm. Its nuclear chromatin is fine and reticular, and there may be one to three pale, bluestaining nucleoli distributed irregularly in the nucleus. There is no nuclear membrane, but the chromatin fibrillae are distributed radially at the periphery of the nucleus. The cytoplasm occasionally contains irregularly sized, round, non-staining vacuoles (Fig. 3).

Proplasmacytes.-The proplasmacyte varies from 15 to $30 \mu$ in diameter. Its nucleus may be centrally or eccentrically placed within the cell. The nuclear chromatin is coarsely reticular and irregularly clumped. A nuclear membrane is suggested at this stage by clumping of the chromatin at the periphery of the nucleus. Nucleoli are absent. The cytoplasm is more abundant in relation to the size of the nucleus than that of the plasmablast. The cytoplasm is basophilic and stains with different intensities of blue from light to dark. Non-staining, irregularly sized round vacuoles are frequently found in the cytoplasm.

Plasmacyte.-The plasmacyte is a cell 8 to $25 \mu$ in diameter that has a relatively large amount of cytoplasm in relation to the size of the nucleus. The nucleus is in rather an eccentric position within the cell, and nuclear chromatin is clumped in an irregular pattern that often resembles a " spoke-wheel."

The definite nuclear membrane appears to be the result of heavy clumping of the chromatin at the periphery of the nucleus. Binucleated and trinucleated plasmacytes are observed. The cytoplasm is diffusely basophilic and stains a light to medium blue. Frequently a perinuclear, clear, non-staining zone is present in the cytoplasm. 
1. Group of seven plasmacytes, two "early homogenous degeneration" cells, and a reticulum cell from Case VII. $\times 1500$.

2. Binucleated plasmacyte from Case VI. $\times 1500$.
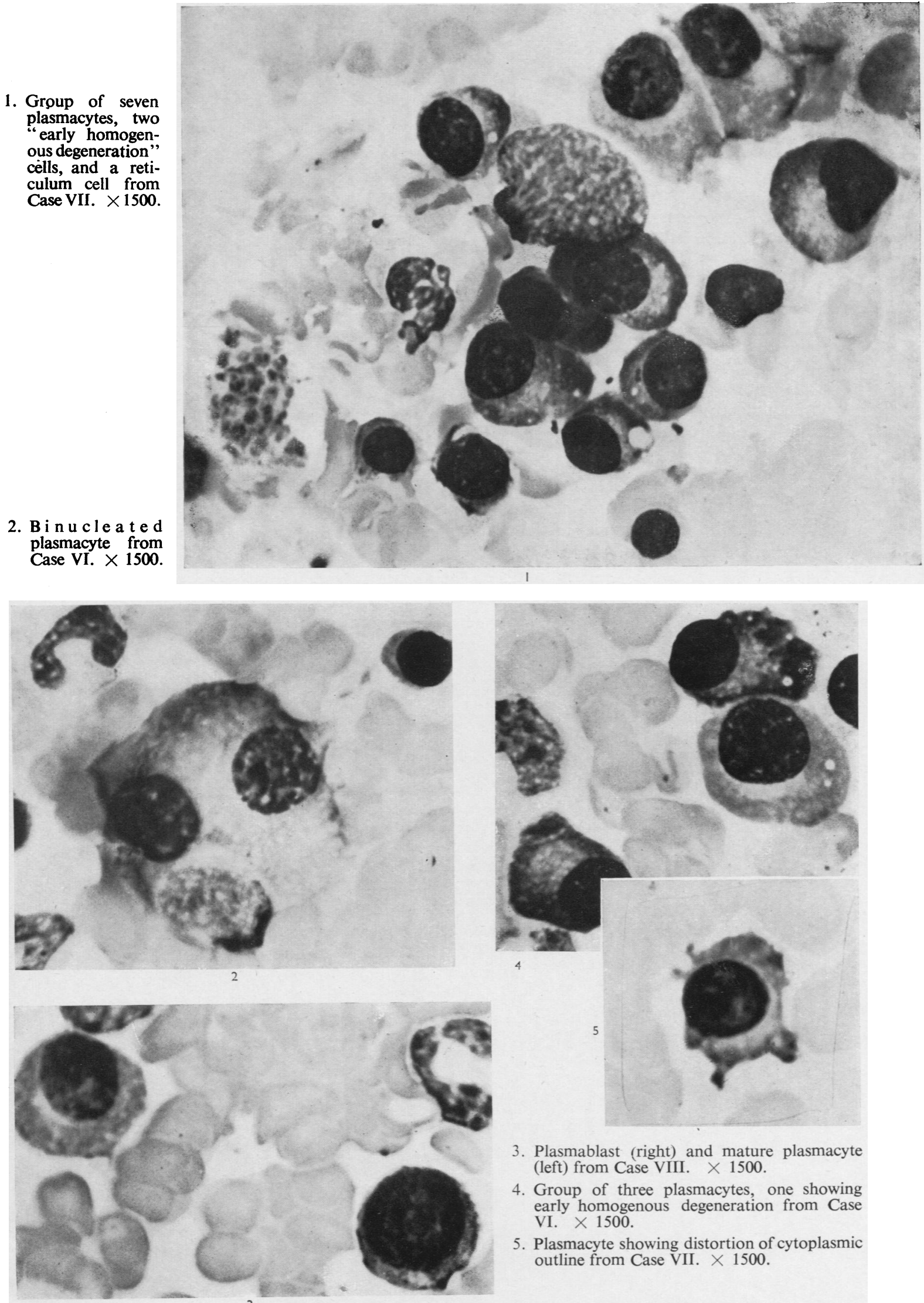

3. Plasmablast (right) and mature plasmacyte (left) from Case VIII. $\times 1500$.

4. Group of three plasmacytes, one showing early homogenous degeneration from Case VI. $\times 1500$.

5. Plasmacyte showing distortion of cytoplasmic outline from Case VII. $\times 1500$. 
Irregularly sized, round, non-staining vacuoles are frequently found in the cytoplasm and are most abundant at the periphery of the cell.

Plasmacyte Showing Early Homogenous Degeneration.-The nucleus remains intact as in the plasmacyte, but the cytoplasm is characterized by uneven light staining. The cell outline remains well defined (Fig. 4).

Degenerative Plasmacytes.-These represent a more advanced state of degeneration than the previous type. The nucleus is pyknotic with early fragmentation. The cytoplasm is less well stained and frequently has a foamy appearance. The cell outline is often indistinct.

Total and Differential Count of the Plasmacytic Elements.-The total percentage of cells of the plasmacytic series was obtained from a count of 1,000 bone marrow cells from each case. The differential count of the plasmacytic elements was obtained by counting 100 cells of the plasmacytic series from each case, and in addition the number of binucleated and trinucleated cells and cells showing mitotic figures was noted.

\section{Case Material and Results}

The ten patients in this series were all suffering from rheumatoid arthritis as judged by the usual clinical criteria, and covered a wide range in age, duration of disease, and severity of present symptoms. These details are included in Table I, together with total and differential plasma cell percentages in the marrows, figures for plasma protein estimations, and sedimentation rates. Table II provides the complete differential counts of 1,000 bone marrow cells from each case, showing normal cellular distributions with the exception of the plasmacytosis.

\section{Discussion}

The Normal Level of Plasma Cells in Sternal Marrow.-Normal differential counts on human sternal marrow published from 13 authoritative sources are summarized by Bodley Scott (1939), and the plasma cell counts in these series give an overall range from 0 to $1.1 \%$; Whitby and Britton (1950) give a range from 0 to $1 \%$ and Custer (1949) from 0 to $1.2 \%$. A level of $2 \%$ or over may certainly be taken as outside the normal maximum.

Bone Marrow Plasmacytosis in Disease.-An increase in plasma cells in the marrow in conditions other than multiple myeloma, plasma cell leukaemia, and diffuse plasma cell myelosis has been noted by a number of authors (Bayrd, 1948 ; Bing, 1940 ; Falconer and Leonard, 1948 ; Kolff and Dhont, 1948) in a wide variety of conditions. These include granulomas and chronic infections, measles, roseola infantum, carcinoma, aplastic anaemia, infectious mononucleosis, monocytic leukaemia, Boeck's sarcoid, cirrhosis, lymphogranuloma inguinale, kala-azar, polyarteritis nodosa, Hodgkin's disease, and some acute infections. The reports are summarized by Fadem and McBirnie (1950), who describe a further six cases with from 5.4 to $23.6 \%$ of plasma cells in the marrow. In their cases, Hodgkin's sarcoma, lymphosarcoma, acute monocytic leukaemia, primary " refractory" anaemia, hiatal hernia, and papilloma of the bladder, the plasmacytosis was encountered during the examination of 100 routine bone marrow preparations. The increased percentage of plasmacytic elements in these conditions is not, however, a constant or even a frequent 


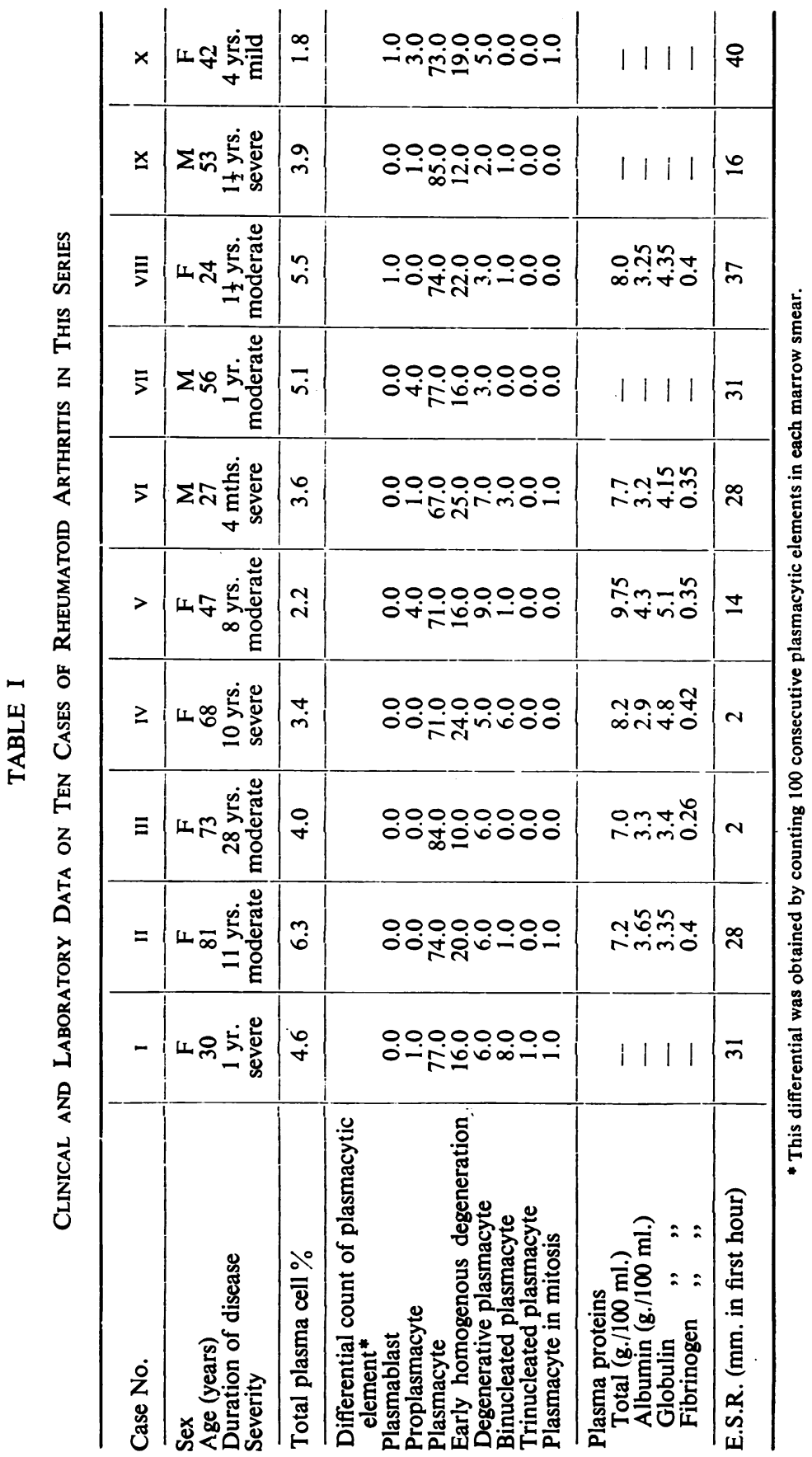




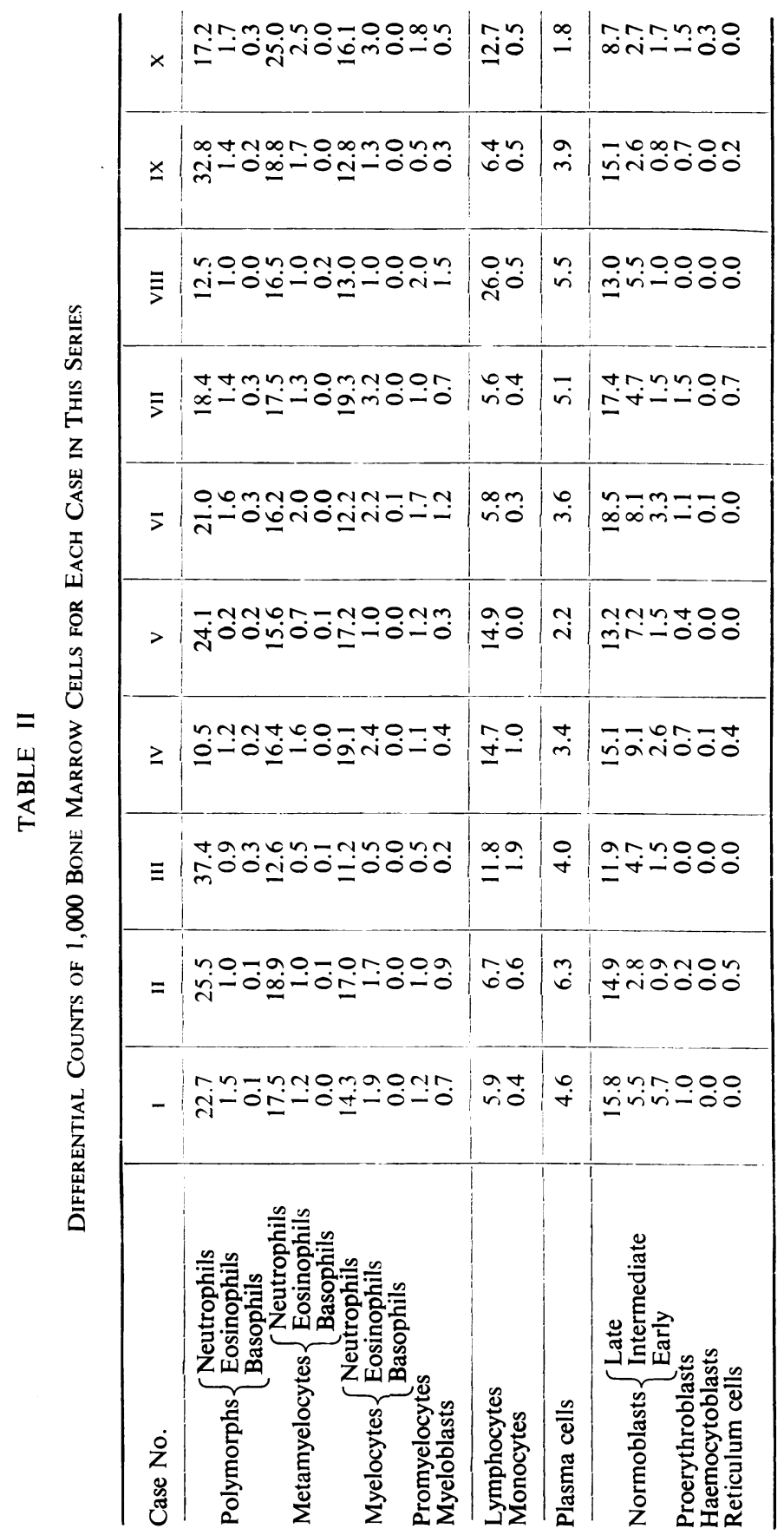


finding, and with the exception of Fadem and McBirnie's report no figures are given of the level of plasmacytosis. No specific reference is made in any of these papers to rheumatoid arthritis, although "chronic infections" are mentioned as associated sometimes with an increase in plasma cells.

The present investigation has shown a remarkably constant increase in the plasma cell content of the marrow in rheumatoid arthritis, figures ranging from 1.8 to $6.3 \%$ being encountered. This finding serves to emphasize that a diagnosis of multiple myelomatosis cannot be based solely on an increase of bone marrow plasma cells over $3 \%$, but must be supported by other evidence. Clumps of plasma cells, up to ten in number, vacuolation, cytoplasmic irregularities of shape and staining, multinucleated cells, and various stages of degeneration, all features which are sometimes regarded as characteristic of myeloma cells, were observed in our material (Figs. 2 and 5).

The plasma samples upon which protein estimations were carried out showed a definite increase in globulin. Although the inaccuracies of the micro-Kjeldahl method render the assessment of individual figures difficult, the constancy of this globulin elevation appears to be significant. More accurate methods in the hands of other investigators have shown that the gamma globulins in rheumatoid arthritis are usually increased (Perlmann and Kaufman, 1946 ; Lövgren, 1945 ; Malmros and Blix, 1946), and the marrow plasmacytosis which we have observed may throw some light on the source of this increase. The hypothesis that foreign proteins are produced at the sites of joint damage becomes less likely if the plasma cells in the marrow are responsible for globulin formation. The results in Table I show that the plasmacytosis and hyperglobulinaemia are not dependent upon the presence of active lesions, since they occur whatever the degree of activity judged by the sedimentation rate. It seems more probable that the increased protein production is a generalized, systemic response, possibly to a circulating antigen, rather than a localized reaction. Support for this conception is lent by the observations of Kolouch (1938), who demonstrated a marked increase in the number of plasma cells in the bone marrow of rabbits, sensitized against Streptococcus viridans during a period when the antibody titre was rising.

Our observations, therefore, favour the view that the hyperglobulinaemia of rheumatoid arthritis is an antibody response, with accompanying plasmacytosis, to an unknown antigen.

\section{Summary}

Ten cases of rheumatoid arthritis showed an increase in bone marrow plasma cells, ranging from 1.8 to $6.3 \%$.

Attention is drawn to the possibility of confusion between the marrow pictures in multiple myeloma and rheumatoid arthritis.

The relationship between hyperglobulinaemia and plasmacytosis is briefly discussed.

The plasma protein estimations were kindly performed by Dr. F. Wild, research chemist, Department of Medicine, Cambridge.

Our thanks are due to Dr. L. C. Martin, Dr. A. P. Dick, and Dr. A. Hanton for kindly allowing us access to patients under their care, and we gratefully acknowledge the advice 
and help given by Sir Lionel Whitby and Dr. M. Hynes. Mr. B. W. Gurner and Mr. R. J. Flemans took the photographs.

The authors carried out this work while holding Elmore Research Studentships.

Bayrd, E. D. (1948). Blood, 3, 987.

\section{REFERENCES}

Bing, J. (1940). Acta med. scand., 103, 565.

and Plum, P. (1937). Ibid., 92, 415.

Custer, R. P. (1949). An Atlas of the Blood and Bone Marrow. W. B. Saunders, London and Philadelphia.

Enders, J. F. (1944). J. clin. Invest., 23, 510.

Fadem, R. S., and McBirnie, J. E. (1950). Blood, 5, 191.

Fagraeus, A. (1948). Acta med. scand., Suppl. 204, p. 18.

Falconer, E. H., and Leonard, M. E. (1948). Ann. intern. Med., 29, 1115.

Hynes, M., and Whitby, L. E. H. (1938). Lancet, $2,249$.

Kagan, B. M. (1943). Amer. J. med. Sci., 206, 309.

Kolff, W. J., and Dhont, J. (1948). Ibid., 215, 405.

Kolouch, F. (1938). Proc. Soc. exp. Biol. N.Y., 39, 147.

Lövgren, O. (1945). Acta med. scand., Suppl. 163, p. 61.

Malmros, H., and Blix, G. (1946). Ibid., Suppl. 170, 280.

Michels, N. A. (1931). Arch. Path., 11, 775.

Perlmann, G. E., and Kaufman, D. (1946). J. clin. Invest., 25, 931.

Scott, R. B. (1939). Quart. J. Med., n.s. 8, 127.

Whitby, L. E. H., and Britton, C. J. C. (1950). Disorders of the Blood, 6th ed. Churchill, London. 